\title{
A SYSTEMATIC APPROACH TO IPR DEFINITION IN COOPERATIVE PROJECTS
}

\author{
L. M. Camarinha-Matos ${ }^{1}$ and H. Afsarmanesh ${ }^{2}$ \\ ${ }^{I}$ New University of Lisbon \\ Quinta da Torre, 2825 Monte Caparica, PORTUGAL, cam@uninova.pt \\ ${ }^{2}$ University of Amsterdam \\ Kruislaan 403, 1098 SJ Amsterdam, THE NETHERLANDS, hamideh@wins.uva.nl
}

The identification of the Intellectual Properties (IP) resulting from a collaborative research and development project and the determination of correct levels of ownership regarding each partner is not only a matter of justice, but also an important requirement to ensure a smooth cooperation. In this paper, an example of a procedure to identify and characterize the IPs resulting from a collaborative project on "infrastructures for virtual enterprises" is presented. The distinction between Intellectual Property and economic value is described by briefly discussing the technological roadmap that turns research results into marketable products.

\section{INTRODUCTION}

During the last 15 years there has been a considerable increase in collaborative research involving both academic and industry teams from different countries. A major example is given by the research programs of the European Union, as is the case of the ESPRIT, BRITE/EURAM, and IST programs. In addition to the European Union countries, these programs have been extended, first to other European countries and more recently to most of the countries in the world. Complementarily, support for cooperation with third countries has also been provided by programs such as ECLA, INCO, and ALFA. Another major example is the IMS (Intelligent Manufacturing Systems) program supporting cooperation among research teams from Europe, Japan, USA, Australia, and Canada. Several other smaller initiatives are also taking place both at the international level, such as Eureka or the programs promoted by the UN Development Program organization, and at a bilateral basis resulting from the many bilateral cooperation agreements between countries.

At the national level as well, many countries have also changed their policy from "single team" research to cooperative research. For instance, in Brazil the PROTEM-CC program [PROTEM-CC, 1999], inspired by the European ESPRIT, promotes the cooperation among research groups and companies from different regions and states of the country.

Although cooperation among researchers has always been a reality, the phenomenon has intensified both due to the mentioned programs and due to the new cooperation facilities provided by Internet. Similar to what is happening in the 
business world, where processes are more and more carried out by networked organizations, such as virtual enterprises, research advances are also more and more the result of cooperative, networked processes. Teams with (mostly) complementary skills join efforts and resources to more effectively perform projects.

In this context, a major issue is the definition of ownership of results produced in cooperation, and more specifically the level of ownership by each partner. Complementary to the intellectual property, there is potential economic value associated to the innovative results of a project.

As a result of the increasing pressure from funding agencies to reach exploitable "products", and the change of values in the "new economy" that favors intangible things (knowledge, relationships, ...), the awareness of the Intellectual Property Rights (IPR) is increasing among the research community. In the case of the European Union programs, dealing with IPR is a mandatory subject for any funded consortium. This is however a difficult subject for which there is not much published examples.

In this paper the approach followed by the Esprit PRODNET II project is described. PRODNET II was a 3-year project (Oct 96-Oct 99) involving ten groups from five countries, including the academic institutions: New University of Lisbon (PT), University of Amsterdam (NL), Federal University of Santa Catarina (BR), Uninova (PT) - software houses: CSIN (PT), Lichen (FR), ProSTEP (DE) - and industrial end-users: Miralago (PT), Herten (BR). The goal was to design and develop an open infrastructure in support of industrial virtual enterprises. The focus of this work was set on supporting the specific needs of the small and medium size enterprises (SME) that constitute a VE, but the achieved results can be as well applied to large companies. A good number of innovative results came out of this project and some efforts towards their exploitation are under way. The scope of this paper covers the Intellectual Property (IP) identification and definition and not the ways to turn these IP values into economic values.

\section{INTELLECTUAL VALUE AND PROPERTY}

\subsection{Valuable results in an $R \& D$ project}

Collaborative R\&D projects, even when addressing industry-motivated problems, do not usually generate products directly marketable. Typical results of such projects are new knowledge and the proof of new concepts via prototypes. Even in the IT area the developed programs are usually at the prototype level, as the resources available to a research project do not support the production of robust industrial products. The concept of Intellectual Property thus represents such intangible and innovative "products" resulting from a research project.

Although this notion of values is obvious to the research community, the increasing involvement of SMEs in research consortia sometimes leads to some misunderstandings. The misunderstanding is mostly around the value of "ideas" versus the "code". Many of these SMEs still do not realize that in an R\&D software development the value of a prototype software module is far less than the embedded knowledge and the innovative concepts, partially demonstrated by the prototype, that are quite valuable. Once a proven concept is clearly understood, it is quite clear how to generate a software product. It is therefore important to thoroughly discuss 
the potential results of the project and who contributes to them in order to reach a common view.

\subsection{Ownership}

Knowledge resulting from a cooperative $R \& D$ project should be the property of those partners that contributed to its generation. When a piece of knowledge is generated with the contribution of several partners, as usually happens in cooperative projects, it is important to determine the level of contribution of each partner and to make a consortium agreement establishing the principles of ownership of these results and their possible use.

It is also typical that when several partners join in a consortium they bring their previous know-how, or knowledge acquired outside the project, that might be necessary to carry out the project. It is therefore important to distinguish between the:

i) Background knowledge (pre-existing know-how) -the knowledge and information owned by a partner in the same field as, or fields related to, the research project, but acquired outside the project.

and

ii) Foreground knowledge or (simply) knowledge -the knowledge and information generated by a partner towards the achievement of project goals.

An example of this distinction is found in the European Commission research contracts [European Commission, 1998]. In an R\&D project, the consortium agreement shall include a detailed identification of all background knowledge brought in by each partner. A related issue is also the access rights for project partners to both types of knowledge. As an illustration, Fig. 1 summarizes the typical access rights used in a European RTD project [IPR-Helpdesk, 1998].

\begin{tabular}{|c|c|c|c|c|}
\hline \multicolumn{5}{|c|}{ Access Rights (AR) } \\
\hline & \multicolumn{2}{|c|}{ Knowledge } & \multicolumn{2}{|c|}{ Pre-existing know-how } \\
\hline Beneficiaries & $\begin{array}{c}\text { For the } \\
\text { execution of } \\
\text { the project }\end{array}$ & For use & $\begin{array}{l}\text { For the } \\
\text { execution of } \\
\text { the project }\end{array}$ & For use \\
\hline $\begin{array}{l}\text { Principal } \\
\text { Contractors }\end{array}$ & $\begin{array}{l}\text { AR on a } \\
\text { royalty-free } \\
\text { basis for } \\
\text { knowledge } \\
\text { necessary to } \\
\text { carry out } \\
\text { their work in } \\
\text { the project. }\end{array}$ & $\begin{array}{l}\text { AR on a royalty-free } \\
\text { basis to all } \\
\text { knowledge resulting } \\
\text { from the project. } \\
\text { AR under preferential } \\
\text { conditions for } \\
\text { knowledge generated } \\
\text { out of the project if } \\
\text { necessary to use the } \\
\text { knowledge resulting } \\
\text { from the project. }\end{array}$ & $\begin{array}{l}\text { AR under } \\
\text { preferential } \\
\text { conditions to } \\
\text { the Pre-existing } \\
\text { know-how } \\
\text { necessary to } \\
\text { carry out their } \\
\text { work in the } \\
\text { project. }\end{array}$ & $\begin{array}{l}\text { AR under } \\
\text { preferential } \\
\text { conditions to } \\
\text { the Pre-existing } \\
\text { know-how } \\
\text { necessary to use } \\
\text { the knowledge } \\
\text { of the project. }\end{array}$ \\
\hline
\end{tabular}

Figure 1 - Access Rights (AR) example in European RTD projects 
Another important issue is the protection mechanisms for the IPs. Members of European funded projects are typically requested to protect the generated knowledge with potential for industrial or commercial application.

In the case of VE-related research, most of the generated IPs knowledge is related to software, algorithms and architectures, models and operation principles. Unfortunately for this type of results the traditional protection mechanisms such as patents or utility models do not properly apply. On the other hand, the copyright mechanism corresponds to a weak form of protection. In particular the European Patent Convention explicitly states that computer programs are not patentable. There are however several ongoing discussions about this subject, namely about the patentability of programs or their internal algorithms when incorporated into machines or processes fulfilling the patentability requirements. More details on these issues and current status can be obtained in the IPR-Helpdesk of the European Commission [IPR-Helpdesk, 1998] or in the ICC site [ICC, 2000].

Nevertheless, if we consider the rapid evolution in the IT area in general, and the $\mathrm{VE}$ in particular, together with the short life cycle of a computer program, a competitive advantage can only be achieved if the innovative ideas produced in a project are rapidly transformed into a product. Only with the good cooperation of (and mutual benefit for) all contributors it is possible to reach an agile productization process for research results. Therefore, in practical terms, cooperation agreements are, perhaps, the most fundamental tools in the practical protection of the IPs generated in a consortium.

\section{THE PRODNET APPROACH TO IPR DEFINITION}

\subsection{Generic iterative approach}

The discussion of IPR in a cooperative research consortium is a rather difficult subject. A number of factors constitute obstacles to a smooth consensus building process such as, for instance, the different perspectives hold by industry and academic partners, the lack of widely known examples in this evolving area, and the peculiarities of the human nature when the focus moves from technical discussions to economic interests.

Starting this process by trying to define a "table of royalties", as tried by some consortia, is not a good approach. It is also important to note that although it is important to discuss this issue before the end of the project, it is also very important to avoid killing the spirit of cooperation that brought a group of partners to cooperate and jointly produce some valuable intellectual property.

Therefore the approach followed in PRODNET II was to first try to identify the list of Intellectual Properties (IPs), independently of their potential economic value and determine the level of contribution (therefore, ownership) of each partner on each IP. Second, to determine a relative value of each IP in comparison to others, in respect to the developed $R \& D$ system. Our observation was that this step although controversial and very difficult, became much more bearable after the partners went through the first step, realizing all the detailed work that is involved in making an innovative system within a cooperation. 


\subsection{Identification of IPs}

Table 1 shows, as an example, the list of IPs resulting from PRODNET II. The basic approach taken here is that the real intellectual value of an R\&D project lies on the original ideas / architectures / approaches / models and not only on concrete software modules. Furthermore it is assumed that programming a software module is an activity that can be trivially pursued once a concept / model is specified. The long-term competitive advantage of companies depends more on the know-how and ideas, than on particular software components that might have a very short life. In this sense, the software components mentioned in the $3^{\text {rd }}$ group of IPs are seen more in terms of their internal architecture (particularly their adaptation to work in a VE environment), the implementation approach, and modularity towards smooth integration, rather than the actual implementations.

Table 1 - Partial PRODNET IPs

\begin{tabular}{|l|l|l|}
\hline IP & Title & Main partner \\
\hline 1 & BASIC INTELLECTUAL PROPERTIES & \\
\hline 1.1 & "PRODNET" Brand Name \& Logo & Partner 5 \\
\hline 1.2 & RTD Project Management Knowledge & Partner 5 \\
\hline 2 & ARCHITECTURES AND MODELS & \\
\hline 2.1 & PRODNET Basic Architecture & Partner 5 \\
\hline 2.2 & PRODNET Hierarchical Coordination Architecture & Partner 5 \\
\hline 2.3 & PRODNET DBP Management & Partner 8 \\
\hline 2.4 & PRODNET DBP Models & Partner 8 \\
\hline 2.5 & Workflow-based Services Coordination & Partner 5 \\
\hline 2.6 & Distributed and Federated Information Management & Partner 6 \\
\hline 2.7 & Integration STEP / EDI & Partner 2 \\
\hline 2.8 & PRODNET Communications Infrastructure Architecture & Partner 7 \\
\hline 2.9 & Partners Search and Selection Architecture & Partner 5 \\
\hline 2.10 & Imprecise \& Incomplete Orders Management & Partner 1 \\
\hline 2.11 & Socio-organizational recommendations for VE implantation & Partner 5 \\
\hline 2.12 & Edition and configuration of DBP and related ACF & Partner 8 \\
\hline 3 & SOFTWARE MODULES & \\
\hline 3.1 & PPC & Partner 1 \\
\hline 3.2 & EDI Module & Partner 2 \\
\hline 3.3 & STEP Module & Partner 3 \\
\hline 3.4 & LCM & Partner 5 \\
\hline 3.5 & DIMS & Partner 6 \\
\hline 3.6 & PCI & Partner 7 \\
\hline 3.7 & LCF & Partner 5 \\
\hline 3.8 & DBPMS & Partner 8 \\
\hline
\end{tabular}

The main partner in this table refers to the partner that had the largest contribution to the related IP. It is usually the coordinator of the task / work package that leads to the development of the IP. This partner is the one that can have a more comprehensive view of the levels of contribution of each other partner to that IP and therefore shall propose objective criteria for the assignment of levels of contribution to the various partners. The initial proposal of the main partner is then refined through interactions with the involved parties until a consensus is reached. 


\subsection{Definition of contributions - criteria per class of IP}

Determining, in an objective way, what is the level of contribution of each partner to a given IP is a very difficult task. A simplistic approach followed by some projects is to just consider the resources allocated by each partner to the task that produced the IP. However this is not a good criterion when considering innovation and intellectual contributions.

Therefore the approach adopted by PRODNET tried to define these contributions based on a number of detailed items directly related to the contents of the IP and that can have, as much as possible, quantifiable and objective measure. The steps followed for each IP are:

-Produce a description of the IP, clearly identifying what it includes.

-Define a list of contributing items that led to the IP and decide on the relative weight of each of these items.

-Determine the contributors and the amount (in percentage) of their contribution to each item.

-Elaborate a table calculating the level of contribution of each partner.

Below we include a few examples of IPs from category 1, 2, and 3 represented in Table 1. Details on the technical concepts and terminology included in the following descriptions can be found in [Camarinha-Matos and Afsarmanesh, 1999].

\section{Example 1: IP 1.1 - PRODNET Brand Name and Logo}

Description: The potential value of the PRODNET brand name and logo comes from the technical quality of the global results, the efforts to make the name and logo known and recognized outside the consortium, and the design of the name and logo.

Criteria to define levels of contribution:

Item 1. Technical quality of the global results. [30\%]

As it is difficult to objectively assess the individual contribution, the decision was to have it equally distributed.

Item 2. Making the name and logo known and recognized outside the consortium. [60\%]

Based on the number of publications, presentations in international events (workshops, conferences, fairs, ...), leaflet, WEB Site, establishment of productive interconnections with other projects, etc.

Item 3. Design of name and logo [10\%].

Please note that the relative weight of each item must be agreed by the consortium, reflecting the way the partners recognize their contribution.

The total level of contribution of each partner to each IP is obtained by a weighted sum, as shown in table 2 .

Table 2 - Levels of contribution to IP 1.1

\begin{tabular}{|l|c|c|c|c|c|c|c|c|c|c|c|}
\hline & & $\begin{array}{c}\text { Partner } \\
1\end{array}$ & $\begin{array}{c}\text { Partner } \\
5\end{array}$ & $\begin{array}{c}\text { Partner } \\
2\end{array}$ & $\begin{array}{c}\text { Partner } \\
6\end{array}$ & $\begin{array}{c}\text { Partner } \\
7\end{array}$ & $\begin{array}{c}\text { Partner } \\
4\end{array}$ & $\begin{array}{c}\text { Partner } \\
5\end{array}$ & $\begin{array}{c}\text { Partner } \\
9\end{array}$ & $\begin{array}{c}\text { Partner } \\
3\end{array}$ & $\begin{array}{c}\text { Partner } \\
10\end{array}$ \\
\hline IP1.1-1 & $30 \%$ & $10 \%$ & $10 \%$ & $10 \%$ & $10 \%$ & $10 \%$ & $10 \%$ & $10 \%$ & $10 \%$ & $10 \%$ & $10 \%$ \\
\hline IP1.1-2 & $60 \%$ & $6.13 \%$ & $40.49 \%$ & $2.45 \%$ & $26.99 \%$ & $7.36 \%$ & $0.00 \%$ & $12.88 \%$ & $1.23 \%$ & $0.00 \%$ & $2.45 \%$ \\
\hline IP1.1-3 & $10 \%$ & $5.00 \%$ & $60.00 \%$ & & $32.5 \%$ & & & $2.50 \%$ & & & \\
\hline $\begin{array}{l}\text { IP1.1 } \\
\text { Level }\end{array}$ & & $7.18 \%$ & $33.29 \%$ & $4.47 \%$ & $22.45 \%$ & $7.42 \%$ & $3.00 \%$ & $10.98 \%$ & $3.74 \%$ & $3.00 \%$ & $4.47 \%$ \\
\hline
\end{tabular}


Example 2: IP 2.1 - PRODNET Basic Architecture

Description: The basic architecture includes the separation of a node (VE member) in two modules (internal module and PRODNET Cooperation Layer - PCL), the basic decomposition of PCL in components, the identification of the main information and control flows, the identification of classes of VEs and roles played by each VE component.

Criteria to define levels of contribution:

1. Initial characterization of the problem area. [15\%]

2. Definition of the basic solution approach. [20\%]

3. Detailed refinement of the architecture approach. [25\%]

4. General contributions to the discussion (mostly in technical meetings). [20\%]

5. Technical coordination of the architecture development. [15\%]

Table 3 - Level of contribution to IP 2.1

\begin{tabular}{|l|c|c|c|c|c|c|c|c|c|}
\hline & & Partner 1 & Partner 5 & Partner 2 & Partner 6 & Partner 7 & Partner 4 & Partner 8 & Partner 9 \\
\hline IP2.1- 1 & $15 \%$ & $40 \%$ & $60 \%$ & & & & & & \\
\hline IP2.1-2 & $20 \%$ & & $70 \%$ & & $30 \%$ & & & & \\
\hline IP2.1-3 & $30 \%$ & & $25 \%$ & & $25 \%$ & $25 \%$ & & $25 \%$ & \\
\hline IP2.1-4 & $20 \%$ & $5 \%$ & $25 \%$ & $10 \%$ & $25 \%$ & $5 \%$ & $5 \%$ & $20 \%$ & $5 \%$ \\
\hline IP2.1-5 & $15 \%$ & & $100 \%$ & & & & & & \\
\hline $\begin{array}{l}\text { IP2.1 } \\
\text { Level }\end{array}$ & & $7.00 \%$ & $50.50 \%$ & $2.00 \%$ & $18.50 \%$ & $8.50 \%$ & $1.00 \%$ & $11.50 \%$ & $1.00 \%$ \\
\hline
\end{tabular}

Sometimes it is convenient to separate the architectural design in a general component (as the IP 2.1) and a few more specialized components or perspectives of the architecture involving a more reduced set of contributors. For instance, IP 2.2.

\section{Example 3: IP 2.2 - PRODNET Hierarchical Coordination Architecture}

Description: This IP refers to the hierarchical - 3 layers - coordination architecture (Core Coordination Layer, Enterprise Management Functionalities, Virtual Enterprise Management Functionalities), including the logical functional structure, supporting information models, information flows, control flows, and interfacing mechanisms.

Criteria to define levels of contribution:

1. Contribution to the main concept. [ $25 \%$ ]

2. Terminology and refinement. [ $20 \%$ ]

3. Detailed design. [ $40 \%$ ]

4. Technical coordination of activity. [ $15 \%$ ]

Table 4 - Level of contribution to IP 2.2

\begin{tabular}{|c|c|c|c|c|}
\hline & & Partner 5 & Partner 6 & Partner 8 \\
\hline IP2.2- 1 & $25 \%$ & $70 \%$ & $20 \%$ & $10 \%$ \\
\hline IP2.2-2 & $20 \%$ & $33 \%$ & $33 \%$ & $33 \%$ \\
\hline IP2.2- 3 & $40 \%$ & $85 \%$ & $15 \%$ & \\
\hline IP2.2- 4 & $15 \%$ & $100 \%$ & & \\
\hline IP2.2 Level & & $73.2 \%$ & $17.7 \%$ & $9.2 \%$ \\
\hline
\end{tabular}


This IP, corresponding to a more innovative item resulted from the joint contribution of 3 academic partners and led to a more advanced architecture then the basic proposal addressed in IP 2.1 .

A normal practice in cooperative projects is to have a few work packages devoted to strongly inter-related work (architecture definition, pilot demonstrator, exploitation plan, etc.) and a set of more specific work packages devoted to particular items, in which a single partner has a major role. The next two examples correspond to IPs resulting from such specific work packages.

\section{Example 4: IP 2.5 - Workflow-based Services Coordination}

Description: This IP refers to the workflow-based approach to coordination of processes and activities inside PCL. It includes the coordination architecture, specialized workflow engine architecture, structuring of services (taxonomies of core and auxiliary services), control flow mechanisms, services invocation mechanisms, supporting information models, interfacing rules, and set of examples of workflow plans (designed for demonstrators).

Criteria to define levels of contribution:

1. Contribution to the main concepts. [30\%]

2. Services specification. [25\%]

3. Contributions to the interfacing principles. [20\%]

4. Design of example workflows (demonstrators). [10\%]

5. Technical coordination of activity. [15\%]

Table 5 - Level of contribution to IP 2.5

\begin{tabular}{|c|c|c|c|c|c|c|c|c|c|c|}
\hline & & $\begin{array}{c}\text { Partner } \\
1\end{array}$ & $\begin{array}{c}\text { Partner } \\
5\end{array}$ & $\begin{array}{c}\text { Partner } \\
2\end{array}$ & $\begin{array}{c}\text { Partner } \\
6\end{array}$ & $\begin{array}{c}\text { Partner } \\
7\end{array}$ & $\begin{array}{c}\text { Partner } \\
4\end{array}$ & $\begin{array}{c}\text { Partner } \\
8\end{array}$ & $\begin{array}{c}\text { Partner } \\
9\end{array}$ & $\begin{array}{c}\text { Partner } \\
3\end{array}$ \\
\hline IP2.5- 1 & $30 \%$ & & $90 \%$ & & $10 \%$ & & & & & \\
\hline IP2.5-2 & $25 \%$ & & $40 \%$ & $25 \%$ & & $35 \%$ & & & & \\
\hline IP2.5-3 & $20 \%$ & $5 \%$ & $30 \%$ & $20 \%$ & $15 \%$ & $30 \%$ & & & & \\
\hline IP2.5- 4 & $10 \%$ & $10 \%$ & $15 \%$ & $10 \%$ & $15 \%$ & $10 \%$ & $10 \%$ & $10 \%$ & $10 \%$ & $10 \%$ \\
\hline IP2.5-5 & $15 \%$ & & $100 \%$ & & & & & & & \\
\hline $\begin{array}{l}\text { IP2.5 } \\
\text { Level }\end{array}$ & & $2.0 \%$ & $59.5 \%$ & $11.3 \%$ & $7.5 \%$ & $15.8 \%$ & $1.0 \%$ & $1.0 \%$ & $1.0 \%$ & $1.0 \%$ \\
\hline
\end{tabular}

As it can be seen in table 5, this IP was mainly the result of the work of partner, although important contributions to the concept are recognized to several other partners.

The next example corresponds also to an IP resulting from a specific work package but illustrating a (more frequent) situation in which smaller contributions from other partners, besides the main responsible, could be identified.

\section{Example 5: IP 2.6-Distributed/Federated Information Management}

Description: This IP refers to the design of the architecture, the models, and the mechanisms that are needed to support the management of integrated information within the VE paradigm. In specific, the designed environment consists of: a pure federated cooperative architecture, provision of information access rights based on the individual role of every other enterprise, preservation of node autonomy and different levels of secure information visibility, and the federated query processing. 
Criteria to define levels of contribution:

1. Contribution to the early concepts [10\%]

2. Problem analysis and requirements identification [20\%]

3. Federated architecture and import/export mechanisms [20\%]

4. Design of the PRODNET integrated schema [16\%]

5. Information visibility hierarchy $[10 \%]$

6. Approach to federated query processing [10\%]

7. General communication approach for the integration of the PCL modules (including the DIMS) $[6 \%]$

8. DIMS interface approach for other PCL modules [6\%]

9. Technical coordination of the activity [2\%]

Table 6 - Level of contribution to IP 2.6

\begin{tabular}{|c|c|c|c|c|c|c|c|}
\hline & & Partner 1 & Partner 5 & Partner 6 & Partner 7 & Partner 4 & Partner 9 \\
\hline IP2.6-1 & $7 \%$ & $20 \%$ & $20 \%$ & $20 \%$ & & $20 \%$ & $20 \%$ \\
\hline IP2.6-2 & $20 \%$ & & & $100 \%$ & & & \\
\hline IP2.6-3 & $20 \%$ & & & $100 \%$ & & & \\
\hline IP2.6-4 & $16 \%$ & & & $100 \%$ & & & \\
\hline IP2.6-5 & $10 \%$ & & & $100 \%$ & & & \\
\hline IP2.6-6 & $10 \%$ & & & $100 \%$ & & & \\
\hline IP2.6-7 & $8 \%$ & & $40 \%$ & $20 \%$ & $40 \%$ & & \\
\hline IP2.6- - & $6 \%$ & & & $100 \%$ & & & \\
\hline IP2.6-9 & $2 \%$ & & & $100 \%$ & & & \\
\hline $\begin{array}{c}\text { IP2.6 } \\
\text { Level }\end{array}$ & $100 \%$ & $1.5 \%$ & $5 \%$ & $87 \%$ & $3.2 \%$ & $1.5 \%$ & $1.5 \%$ \\
\hline
\end{tabular}

Finally, the next two examples illustrate the case of IPs associated to software modules development.

\section{Example 6: IP 3.4-Local Coordination Module [Workflow Manager]}

Description: Specification and logical design of the software module for local coordination (workflow-based), including the implementation approach, interfacing rules, supporting information models, illustrative examples (demonstrator-related), assessment of results, and a prototype implementation.

Criteria to define levels of contribution:

1. Software specification and design. [20\%]

2. Interfacing specification. [20\%]

3. Example of workflow plans and assessment. [5\%]

4. Prototype development. [40\%]

5. Technical coordination of activity. [15\%]

Table 7 -Level of contribution to IP 3.4

\begin{tabular}{|l|l|l|l|l|l|l|l|l|l|l|l|}
\hline & & $\begin{array}{l}\text { Partner } \\
1\end{array}$ & $\begin{array}{l}\text { Partner } \\
5\end{array}$ & $\begin{array}{l}\text { Partner } \\
2\end{array}$ & $\begin{array}{l}\text { Partner } \\
6\end{array}$ & $\begin{array}{l}\text { Partner } \\
7\end{array}$ & $\begin{array}{l}\text { Partner } \\
4\end{array}$ & $\begin{array}{l}\text { Partner } \\
8\end{array}$ & $\begin{array}{l}\text { Partner } \\
9\end{array}$ & $\begin{array}{l}\text { Partner } \\
3\end{array}$ & $\begin{array}{l}\text { Partner } \\
10\end{array}$ \\
\hline IP3.4- & $20 \%$ & & $100 \%$ & & & & & & & & \\
\hline IP3.4-2 & $20 \%$ & & $40 \%$ & $15 \%$ & $20 \%$ & $25 \%$ & & & & & \\
\hline IP3.4-3 & $5 \%$ & $11 \%$ & $11 \%$ & $11 \%$ & $11 \%$ & $11 \%$ & $11 \%$ & $11 \%$ & $11 \%$ & $11 \%$ & \\
\hline IP3.4- & $40 \%$ & & $100 \%$ & & & & & & & & \\
\hline IP3.4- 5 & $15 \%$ & & $100 \%$ & & & & & & & & \\
\hline $\begin{array}{l}\text { IP3.4 } \\
\text { Level }\end{array}$ & $0.6 \%$ & $83.6 \%$ & $3.6 \%$ & $4.6 \%$ & $5.6 \%$ & $0.6 \%$ & $0.6 \%$ & $0.6 \%$ & $0.6 \%$ & $0.0 \%$ \\
\hline
\end{tabular}


Example 7: IP 3.5-DIMS software development

Description: The software of the Distributed Information Management System (DIMS) provides the information repository for the PCL. It develops and satisfies both the application requirements and the modeling approach described in IP 2.6 above. The implementation of the federated database and federated query processing is achieved using the Oracle database system as a platform. The design of the implementation architecture, or at least a big part of it, is generalized enough to be used for other development plans for the DIMS on top of other commercial database system platforms.

Criteria to define levels of contribution:

1. Implementation architecture design and software specification [15\%]

2. Development of models for the data of the PCL modules [15\%]

3. Specification of Interfaces to use DIMS from other modules [10\%]

4. Prototyping the (general) communication approach for the integration of PCL modules [5\%]

5. Prototype development [50\%]

6. Technical coordination of activity. [5\%]

Table 8 - Level of contribution to IP 3.5.

\begin{tabular}{|c|c|c|c|c|c|c|c|c|}
\hline & & $\begin{array}{c}\text { Partner } \\
8\end{array}$ & $\begin{array}{c}\text { Partner } \\
1\end{array}$ & $\begin{array}{c}\text { Partner } \\
5\end{array}$ & $\begin{array}{c}\text { Partner } \\
2\end{array}$ & $\begin{array}{c}\text { Partner } \\
6\end{array}$ & $\begin{array}{c}\text { Partner } \\
7\end{array}$ & $\begin{array}{c}\text { Partner } \\
3\end{array}$ \\
\hline IP3.5-1 & $15 \%$ & & & & & $100 \%$ & & \\
\hline IP3.5-2 & $15 \%$ & $20 \%$ & $10 \%$ & $10 \%$ & $10 \%$ & $40 \%$ & $10 \%$ & $5 \%$ \\
\hline IP3.5-3 & $10 \%$ & $5 \%$ & $5 \%$ & $5 \%$ & $5 \%$ & $75 \%$ & $5 \%$ & \\
\hline IP3.5-4 & $5 \%$ & & & $20 \%$ & & 40 & $40 \%$ & \\
\hline IP3.5-5 & $50 \%$ & & & & & $100 \%$ & & \\
\hline IP3.5-6 & $5 \%$ & & & & & $100 \%$ & & \\
\hline $\begin{array}{c}\text { IP3.5 } \\
\text { Level }\end{array}$ & $\begin{array}{c}100 \\
\%\end{array}$ & $3 \%$ & $2 \%$ & $3 \%$ & $2 \%$ & $85 \%$ & $4 \%$ & $1 \%$ \\
\hline
\end{tabular}

It is interesting to notice that in this IP there is a much higher level of cooperation among partners than in the related example IP 2.6. While IP 2.6 was mostly conceptual design, the implementation architecture considered in this IP really required the contribution of most of the other partners. This example confirms the appropriateness of separating the two classes of IPs (2 and 3).

It is important to emphasize that the described steps led to the identification of quantified levels of contribution of each partner to each IP, but this doesn't (directly) reflect an economic value.

\section{EXPLOITATION OF RESULTS}

Although $\mathrm{R} \& \mathrm{D}$ is a very important phase in the innovation process, the postresearch phase of transforming the created knowledge into products requires considerable efforts and investments. For instance, some important steps are: reimplementation of components in a robust and business-oriented way, application of quality procedures and other regulations, documentation development, training materials development, systems integration, etc. 
It is also important to note that one product may integrate contributions from various IPs and that not all IPs are directly exploitable at the same time. There is also a case in which a new component based on research results is integrated with legacy products of one partner.

It is therefore important to reach an agreement on the assessment of which IPs are contributing to a given product (or sub-product) and what is the relative weight of these IPs in the global productization process, as a way to assign an economic value to each exploitation of the IP, as also mentioned earlier in section 3.1.

Furthermore, the roles and responsibilities of each partner in the full life cycle of each product have to be clearly defined. In this process it is important to understand the nature of the academic institutions that are not usually prepared to give life cycle support to a product. In this case the most adequate process is to promote the complete knowledge transfer to a company that will take over the responsibility of maintaining the product. Most university groups do not even have the engineering resources to invest on the productization steps. Therefore, their role can only be assisting the companies that will perform the productization.

The ways of distribution of the benefits resulting from the exploitation of research results have therefore to take into account, not only the initial contribution to the IPs, but also the role played by each partner in the subsequent phases. In order to cover the various possibilities, several mechanisms such as lump sum payments, simple royalties, incremental royalties, etc., have been devised [Kamm, 1996].

In the case of the VE area it is also important to notice that this "market" has special characteristics. Although there have been many research projects developing tools and infrastructures to support VEs, the characteristics of the market are still unclear. The productization of any promising idea/solution depends on the demonstrated success considering the required efforts and the financial advantages to the potential investors. The virtual enterprise market seems to have a very interesting potential mainly because it is a logical consequence of the ongoing efforts to increase the electronic information exchange among enterprises. But a major difficulty is that the target client for a VE support infrastructure product is not a single enterprise, but a group of autonomous enterprises. Unlike the case of other enterprise applications (ERP, PDM, CAD), it is not sufficient to sell the new product to a single company. A VE infrastructure only becomes useful if adopted by the various members of a VE. The main difficulty here is that it requires an extended adherence of other enterprises to the proposed technological innovation. In fact an enterprise that decides to enter a virtual enterprise needs at least that one or more of its partners also adhere to the same technological solution.

Furthermore, more than technological working solutions, a significant set of services involving knowledge transfer is necessary to put the integrated "machine" to work. Most of the times a new installed component, to run in some enterprise business area, has to deal with applications from other vendors or even tools developed in-house. This scenario creates complex integration situations with the added difficulty to assign responsibilities in case of problems, simply because it is difficult to determine their origin. In this case non-commercial IP contributors can assist in training, analysis of the problem, and consulting companies for solutions.

When companies are organized in clusters it might be feasible to convince all members of the cluster to adopt a common infrastructure. Otherwise, the market penetration of this kind of products is difficult. One possibility is to distribute them 
free of charge - in order to create a large base of users - and create a market of associated services.

In the above scenario, the determination of economic compensations for the IP contributors becomes even more difficult, as the more "tangible" products are offered free of charge. Nevertheless these products were essential for the creation of the services business and, therefore, there is a need to compensate the intellectual property contributors.

The area of Intellectual Property and its relation to the exploitation of project results is a difficult subject requiring further exchange of experiences and assessment of trends. Meanwhile general principles of fairness shall be adopted and the discussion of the complete process of "going from research to the market", giving all participants a clear picture of the challenges involved, is a necessary step to facilitate consensus.

\section{CONCLUSIONS}

Although the IPR issues more and more need to be addressed by collaborative research projects, there is a lack of published examples that can be used as a guide in the discussion of cooperation agreements.

The approach introduced in PRODNET II represents an attempt towards an objective and systematic identification of the levels of contribution of each partner to each IP generated by the consortium.

Further work and exchange of experiences is necessary in order to properly address the relationships between the Intellectual Property and the economic benefits induced by the project results.

\section{REFERENCES}

1. Camarinha-Matos, L.M.; Afsarmanesh, H. - Infrastructures for Virtual Enterprises: Networking industrial enterprises, Kluwer Academic Publishers, Oct 99, ISBN 0-7923-8639-6.

2. European Commission - Cost Reimbursement Contract for Community Activities in the filed of Research and Technological Development, Brussels.

3. IPR-Helpdesk: http://www.cordis.lu/ipr-helpdesk/

4. CORDIS: http://www.cordis.lu

5. PROTEM-CC: Proceedings of Projects Evaluation Workshop, Rio de Janeiro, Brazil, 5-7 May 1999.

6. Kamm, C. - Technology management: commercial exploitation of technologies - commercial conditions and pricing in technology transfer agreements, Proceedings of the ESPRITCOPERNICUS Symposium on Quality, Logistics and Technology Management, Budapest, 9-10 Dec 1996.

7. ICC - Intellectual property explained, http://www.iccwbo.org/home/intellectual_property/presentation/index.asp 